\title{
Moisture Resistance Coating of Packaging Paper from Biobased Silylated Soybean Oil
}

\author{
Chetan Tambe, Daniel Graiver and Ramani Narayan ${ }^{1}$ \\ Michigan State University, Department of Chemical Engineering and Material Science,
} East Lansing, MI. 48823, USA

\begin{abstract}
:
The moisture resistance of Kraft paper was greatly improved when it was coated with silylated soybean oil that was cured via silanol condensation. This moisture barrier coating was prepared from LowSat $®$ Soybean oil that was grafted with vinyltrimethoxysilane (VTMS) using a relatively simple process based on the "Ene reaction". The viscosity of the resulting oil was unaffected by the silylation reaction and remained low $(32 \mathrm{cPs})$. Thus, the paper coating process required no solvent, additional diluent or the need to emulsify the oil which provided a convenient onecomponent cure system. Dibutyltin dilaurate (DBTDL) was found to be an effective condensation catalyst and under optimal conditions complete cure was achieved in a short period of time. The cure rate was a function of the catalyst concentration, available water and the temperature. Initially, Kraft papers were coated with the silylated soybean oil in the lab and this process was followed by a pilot scale-up using a commercial gravure roll coater. Cobb values and water vapor transmission rate indicated the cured coating provided a good barrier coating. Scanning electron microscopy (SEM) images of the coated paper confirmed a uniform coating with good adhesion of the coating material to the paper.
\end{abstract}

Keywords: Silylated soybean oil, Paper packaging, Moisture resistance, Kraft paper, Cobb values,

\footnotetext{
${ }^{1}$ Corresponding author: Ramani Narayan, Michigan State University, Dept. of Chem. Eng. and Mater. Sci. E. Lansing, MI. 48824, Phone: (517) 719-7163 email: narayan@msu.edu
} 


\section{Introduction:}

Paper bags are widely used in the packaging industry since the paper is widely recognized as a safe and environmentally-friendly material due to its biodegradability. One of the major requirements for papers that are used in the packaging industry is the need to provide a moisture barrier since such barrier plays a critical role in preserving the food quality. Structurally, a paper consists of a porous cellulose made up of micro-fibrils composed of long-chain crystalline cellulose regions with pockets of amorphous regions. The cellulose structure is inherently hydrophilic due to the multiple hydroxyl groups. In addition, the fiber network is porous, which further limits the moisture barrier of the paper [1]. Consequently, it is well known that water molecules are transported in papers by diffusion of water vapor through the void spaces as well as in a condensed form through fiber cell walls [2]. It follows that papers with high porosity and large pore size, such as Kraft paper, have poor moisture barrier. However, Kraft paper is commonly used in the paper packaging industry because of its low cost of production and thus, it has to be coated with a good moisture barrier material with minimal impact on its cost [3].

Historically, common paper coatings were prepared from wax. Wax is relatively cheap and it provided reasonably good moisture barrier as well as grease resistance properties. Although wax coating is still available today, it has been largely replaced by plastic films like polyolefin [4], polyethylene [5], polyethylene terephthalate (PET), polybutylene terephthalate (PBT) [6], polyvinyl alcohol [7] and fluorocarbons [8,9] that provide superior performance. However, the use of these synthetic polymers led to the loss of the inherent biodegradability and recyclability of the paper. The desire to prolong shelf-life and enhance food quality whilst reducing packaging waste created an interest in using polymers from renewable resources that can replace synthetic films. Indeed, there is a great interest in the packaging industry in environmentally friendly paper 
coating materials that are biodegradable [10] and several biopolymers have been investigated as coating for paper packaging. These polymeric materials are based on renewable resources like polysaccharides, lipids, proteins and their combinations [11-13]. However, coatings derived from protein, hydrocolloidal polysaccharide and hydroxypropyl methylcellulose had poor water barrier due to their hydrophilic nature whereby the inherently hydrophobic lipids are preferred. It was noted, however, that although lipid coatings can provide good moisture barrier, they have certain disadvantages including oily surface, brittleness, lack of homogeneity and the presence of pinholes and cracks in the surface of the coating. These studies further revealed that in addition to god and effective coating, the biobased composition needs to be a low viscosity material that is fast drying and can provide a uniformity coating over the porous paper substrate. It is anticipated that successful coatings should allow greater use of Kraft paper in daily life as packaging of fresh food but also as coating for paper bags used for waste food collections.

In addition to advancements in the coating materials, there have been remarkable advancements in the technology of the paper coating process itself ranging from applying and distributing of the coating material using brush like paints in early processes to the use of roll or jet applicators that are used today. The most common choice in modern day paper coating technology is the use the gravure roll coaters which allows to accurately manage the coating thickness using a blades or a metering bar[14, 15]. Indeed, advances in, both, the paper coating materials and the coating process are mainly attributed to the needs and advent of the printing[16] and the packaging[17-19] industries. Most critical factors for the gravure roll coaters are the viscosity of the coating material, the rolling speed and the oven temperature.

Plant oils are readily available, low cost, non-toxic and inherently non-volatile low viscosity oils that are renewable raw materials. The unsaturation present in the fatty acids of these oils have 
been used in the coatings industry in the past [20]. Natural drying oils have been commercially used for centuries in the paints and coating industries [21-25]. The most common example of such oils is linseed oil that contains a high degree of unsaturation (as it contains high concentrations of linoleic and oleic fatty acids). Upon exposure to oxygen in the air, linseed oil is readily oxidized and cross-linked to a rigid film [26]. Although linseed oil has been used as an ingredient in various industrial paints and coating formulations, coatings derived from linseed oil are very brittle and tend to yellow upon aging. Furthermore, drying oils derived from linseed oil are generally highly viscous and require the use of organic diluents or emulsification in order to lower their viscosity, which further increases the time of cure as the excess solvent needs to be removed from the system. Additionally, this oxidation cure mechanism requires toxic catalysts (e.g., transition metal salts based on cobalt and lead) to accelerate the crosslinking reactions [27-29]. These issues hindered the use of linseed oil and similar highly unsaturated natural oils in the paper coating industries.

Much work has been published on epoxidation of the unsaturated fatty acids where the double bond was converted to reactive epoxides [30-32]. This epoxidized oil could then further be cured with compounds like acrylic acid, isocyanates, etc. Unfortunately, this approach requires multisteps processes, which in turns increases the cost of the coating materials. Furthermore, curing of these materials is limited by relatively long cure time and high temperatures.

In this work, a low viscosity silylated soybean oil has been used as a paper coating material to provide a moisture barrier coating over Kraft paper. The silylation of soybean oil was accomplished in a single step process $[33,34]$ resulting in a stable oil when kept in a close container away from atmospheric moisture. Upon exposure to moisture, it quickly cures to yield a good hydrophobic barrier coating. Factors affecting the coating process, the cure reactions to form a barrier network and the properties of the coated papers are described. This non plastic, 
biobased coating was developed to be used as a waste bag on board ships for collection of food and other bio-wastes that can be discharged into the ocean where the paper and the coating would be completely biodegrade.

\section{Material and methods}

LowSat ${ }^{\circledR}$ soybean oil was kindly provided by Zeeland Farm Services, Inc. (MI, USA). Vinyltrimethoxysilane (VTMS) was purchased from Gelest, Inc. (PA, USA). Luperox-101 and Dibutyltin dilaurate (DBTDL) were purchased from Sigma-Aldrich (MO, USA). Kraft papers with weights of $0.27 \mathrm{~kg} / \mathrm{m}^{2}\left(60 \mathrm{lb} / 1000 \mathrm{ft}^{2}\right)$ and $0.38 \mathrm{~kg} / \mathrm{m}^{2}\left(78 \mathrm{lb} / 3000 \mathrm{ft}^{2}\right)$ were purchased from KapStone Paper and Packaging Corporation (IL, USA). All other chemicals were reagent grade and were used without further purification unless noted.

\section{Silylation of Soybean Oil}

The silylation of LowSat® soybean oil was performed in a 5 gallon high-pressure stainless steel reactor from PARR Instrument Company (IL, USA) as shown schematically in Figure 1. In a typical experiment, lowSat ${ }^{\circledR}$ soybean oil (1 mole, 874 grams) and VTMS (3 moles, 444 grams) were premixed with 1 wt. \% (87 grams) of Luperox-101 catalyst. Nitrogen gas was purged through the reactor feed port to ensure an inert environment inside the reaction vessel. The silylation reaction was carried out at a constant temperature $\left(250^{\circ} \mathrm{C}\right)$ under continuous stirring for 20 hours and the pressure was monitored by a pressure gauge. Since the reaction temperature was higher than the boiling point of VTMS, the pressure continuously decreased as unreacted VTMS was grafted onto the soybean oil. Samples were drawn from the reaction mixture through the sampling port at regular time intervals to determine the extent of the grafting reaction. 
The extent of the silylated soybean oil product was measured by Thermogravimetric (TGA) analysis (TA instruments, New Castle, USA; Hi-Res TGA 2950). In a typical experiment, a sample was heated quickly to $130^{\circ} \mathrm{C}$ (which is above the $123^{\circ} \mathrm{C}$ boiling point of VTMS) and was held at this temperature for 30 minutes. Under these adiabatic conditions any free (ungrafted) VTMS was removed from the sample and the extent of grafting was calculated from the weight loss using equation 1.

$$
\% \text { Grafting }=\frac{w t \% \text { VTMS in feed-wt } \% \text { VTMS ungrafted }}{w t \% \text { VTMS in feed }} \text { X100 Eq. [1] }
$$

\section{Network formation}

Upon exposing the methoxysilane to moisture, the hydrolytically unstable siloxy bonds (e.g. $\left.\mathrm{Si}-\mathrm{OCH}_{3}\right)$ were hydrolyzed and the resulting silanols $(\mathrm{Si}-\mathrm{OH})$ were condensed in the presence of the DBTDL catalyst to form stable siloxane crosslinks ( $\mathrm{Si}-\mathrm{O}-\mathrm{Si}$ ) as shown in Scheme 2 [34]. The cure rate of this moisture activated crosslink reactions was studied using different DBTDL catalyst concentrations, temperature and different water content. The cure rate was determined by the change in the viscosity as a function of time using a Brookfield viscometer-LDVE-E model (MA. USA) equipped with Spindle 61. In order to ensure adequate results in these tests, the torque was kept in the range of $10-50 \%$.

\section{Paper coating}

Kraft papers with two different weights $\left(0.27 \mathrm{~kg} / \mathrm{m}^{2}\right.$ and $\left.0.38 \mathrm{~kg} / \mathrm{m}^{2}\right)$ were first coated using a laboratory Roll-Lab Coater (ECS-1211-M1EPDM119) from Euclid Coating Systems (ECS). In a typical experiment, the paper was secured to the ECS roller and the blade pressure was set at 40 psi. Under these conditions the silylated oil was spread evenly across the blade-roller interface to 
produce an even and complete coverage over the entire surface of the paper. The coated papers were then post-cured in an oven at $80^{\circ} \mathrm{C}$ for 30 minutes to ensure the crosslink reaction had been completed. The coat weight was calculated by simply subtracting the weight of an uncoated paper of known surface area from the weight of a coated paper.

Large-scale coatings were conducted in a common Gravure coating system. The set up that was used for the gravure roll coatings is illustrated in Figure 2. In this process, the paper was thoroughly dried prior to the coating and then rolled over between the two-roll gravure coater from the feed roll. The coating mixture (silylated LowSat ${ }^{\circledR}$ soybean oil, DBTDL catalyst, $3 \%$ wt. and water, 3 wt. \%) was pumped from the oil bath held at RT and applied to the etched pattern of the rollers by capillary action and then onto the paper as it passed between the nip of the gravure roll and the backup roll. The coated paper was then passed through an oven set at $80^{\circ} \mathrm{C}$ to ensure complete cure before it was collected on the receiving roll. The line speed of the paper throughout the coating process was kept constant at $2.7 \mathrm{~m} / \mathrm{min}$.

\section{Characterizations}

The Attenuated Total Reflection-Fourier Transform Infrared (ATR-FTIR) spectra were acquired on a Schimadzu IRAffinity-1 spectrometer (Tokyo, Japan) equipped with a single refelction ATR system (PIKE Technologies, MIRacle ATR, Madison, USA). All spectra were acquired between $600-4000 \mathrm{~cm}-1$ using 32 scans at a resolution of $4 \mathrm{~cm}-1$.

Contact angle measurements were performed using Kruss Contact Angle Equipment (DSA 100, Kruss USA, NC, USA) by placing a drop of $4 \mu \mathrm{L}$ of water onto the film surface and measuring the contact angle using a static contact angle measurement method. HPLC grade distilled water was used for all measurements. The coated and uncoated paper samples were cut $(3 \mathrm{~cm} \mathrm{X} 10 \mathrm{~cm})$ and glued to a glass slide of the same dimensions. For the uncoated paper samples, the contact 
angle measurements were somewhat difficult due to water absorption into the paper which caused a continuous decrease in the observed contact angle. For consistency, all measurements were taken within the first 5 seconds where the geometry of the water drop was found to be relatively stable. Unlike the uncoated paper, the geometry of the water drop on the coated paper was found to be stable for as long as 2 minutes clearly indicating much lower water uptake despite of rough nature of the substrate. The sessile drop method (ASTM D7334) was used to analyze the contact angle.

The water resistance of the coated papers was measured using a 2 minute Cobb test following a standard TAPPI T441 procedure. This test consists of placing a $12.5 \times 12.5 \mathrm{~cm}$ square piece of coated paper that was cut randomly from a stack of coated papers on a neoprene mat and clamping it in the Cobb cylinder. Then, $100 \mathrm{~mL}$ water was poured over the clamped areas $\left(100 \mathrm{~cm}^{2}\right)$ and kept in place for 2 minutes. The water was then drained from the paper, any excess water was removed using a 10kg roller and the weight of the paper was measured and compared to the initial dry weight. The Cobb value based on these experiments is defined as the change in the weight (in grams per meter ${ }^{2}$ ) as shown in eq. [2].

$$
\text { Cobb value }(\mathrm{gsm})=\frac{\text { final paper weight }(\mathrm{g})-\text { initial paper weight }(\mathrm{g})}{0.01 \mathrm{~m}^{2}} \quad \text { Eq. [2] }
$$

The Water Vapor Transmission Rate (WVTR) was determined using a PermtranTM W3/33 analyzer (MOCON, Minneapolis, MN, USA) following ASTM standard F1249-05. For these measurements, pieces of the coated and uncoated Kraft papers were masked on both sides with aluminum foil using an adhesive baking (Mc-Master Carr, Aurora, Ohio, USA) leaving a welldefined test area of $3.14 \mathrm{~cm}^{2}$. The thicknesses of these paper samples was measured using a micrometer (Dial Thickness gauge 7301, Mitutoyo, Tokyo, Japan) with a $0.001 \mathrm{~mm}$ accuracy. The 
average thickness for the uncoated papers was $0.096 \mathrm{~mm}$ and $0.099 \mathrm{~mm}$ for the coated papers. For all WVTR measurements, the temperature was maintained at $27 \pm 3^{\circ} \mathrm{C}$ and relative humidity of $37 \%$ using humidity probes. Three replicates were carried out for each type of paper.

Scanning electron microscopy (SEM, Japan Electron Optics Laboratories, Japan, JEOL$6400 \mathrm{~V}$ ) was used to study the surface morphology of the coated and compare it with the uncoated papers. Each sample was first coated with gold using a gold sputter coating device to enhance the details. The samples were observed under different magnifications from $20 \mu \mathrm{m}$ to $200 \mu \mathrm{m}$.

\section{Results and Discussions}

LowSat ${ }^{\circledR}$ soybean oil was chosen for the grafting reaction since the lower saturated content ensures that a coating prepared from it will contain no unreacted triglycerides. Regular soybean oil contains an average of 4.5 double bonds on the fatty acids chains per triglyceride, whereby, LowSat ${ }^{\circledR}$ soybean oil contains an average of 5.1 double bonds per triglyceride. The higher degree of unsaturation ensures that there are essentially no triglycerides that are composed of only saturated fatty acids as these saturated fatty acid triglycerides cannot be silylated. Thus, they will not participate in the network and will remain as free oil in the coating negatively impacting the surface properties of the coating. Specifically, LowSat ${ }^{\circledR}$ soybean oil contains $75.5 \%$ oleic acid (a single double bond), 35\% linolenic acid ( 3 double bonds), 15\% linoleic acid ( 2 double bonds), $3 \%$ palmitic acid and 3\% stearic acid (no double bonds). Statistically, there is a negligible concentration of triglycerides composed of 3 saturated fatty acids [34].

The cure mechanism and network formation in this system follow the typical cure of silanes that have been used extensively in inks, paints and adhesives containing silanes [35-37]. In these systems the crosslink network is obtained when the hydrolytically unstable siloxy groups (Si-O- 
C) in the alkoxysilanes are hydrolyzed upon exposure to moisture and yield silanols ( $\mathrm{Si}-\mathrm{OH})$. In the presence of appropriate condensation catalysts these silanols further condense to yield stable siloxane bonds ( $\mathrm{Si}-\mathrm{O}-\mathrm{Si}$ ). Provided multiple silanols are available, a stable covalent network is formed.

\section{Silylation}

Since hydrosilylation is only suitable for silylation of terminal double bonds, the preferred approach to graft a silane onto non-terminal double bonds of the unsaturated fatty acids in the soybean oil is via the 'Ene reaction' (Scheme 1). The general synthetic and mechanistic aspects of this reaction with respect to olefins have been reviewed elsewhere [38-40] and a feasibility study dealing with grafting of VTMS onto soybean oil is available [34].

In this system, the 'Ene reaction' proceeds smoothly due to the fact that vinylsilanes do not undergo thermal polymerization like common vinyl monomers such as styrene, acrylates and similar vinyl monomers [41, 42]. Indeed, no apparent oligomerization of the oil was observed under the reaction conditions and the viscosity of the silylated soybean oil remained very low (32 cPs). The low viscosity of the oil was found to be extremely useful as it required no diluent and could be used directly in the coating process.

The yield of the silylation reaction was calculated by equation 1 from the weight loss in the isothermal TGA analyses. It was observed that the extent of grafting was directly proportional to the reaction time as shown in Figure 3 and the kinetics of this reaction was found to follow a second order reaction rate [34]. It is important to point out that there is no need to remove the small fraction of unreacted VTMS from the silylated oil product as these free silanes are miscible in the oil and will be hydrolyzed and condense with the grafted VTMS fraction to be an integral part of the crosslinked network. 
No change in the viscosity of the silylated soybean oil was observed (avg. $40 \mathrm{cPs}$ ) upon storage in a closed container over a period of 8 months indicating good stability of the oil. However, it should be emphasized, that during storage the silylated soy oil must be kept under an inert atmosphere away from moisture as the presence of moist atmosphere over the oil surface in a close container will lead to a formation of a crusty surface layer in contact with the moist air.

\section{Moisture Cure}

One-component, moisture activated cure of silicones is well known [35-37, 43] and combines several advantages over other cure systems. The general network formation when the silylated oil is exposed to moisture is shown in Scheme 2. The methoxy groups on vinylsilanes are easily hydrolyzed initially and, in the presence of a condensation catalyst, condense to form a cured network crosslinked with stable Si-O-Si linkages. After applying the oil onto the surface of the paper, the cure process was controlled by adjusting the concentration of the catalyst, the moisture content and the temperature. In this study the catalyst concentration was varied from $1 \mathrm{wt}$. \% to 4 wt. \%, along with varying moisture content from $2 \mathrm{wt}$. \% to $4 \mathrm{wt}$. \%. Under these conditions high rates of cure were observed at temperatures above $80^{\circ} \mathrm{C}$. The crosslinking reaction was followed by the change in the viscosity of the oil over time (Figure 4).

It was observed that the rate of cure was directly proportional to the concentration of the catalyst and the water content. Yet, it is important to note that when the water content was less than $3 \mathrm{wt} . \%$, only partial hydrolysis was attained and the initial viscosity of the reaction mixture increased slightly but then remained almost constant over a long period of time. This partial hydrolysis and condensation allowed us to control the initial viscosity of the oil to be sufficiently high so it remained on the surface of the paper with minimum soaking into the interior of the paper yet, it was not too high so as to interfere with the coating process and the coating equipment. 


\section{Paper coatings}

The silylated soybean oil was coated on the paper, allowed to cure and the water barrier of the cured coating was examined. Two types of paper (Kraft \#60 and Kraft\#78) were coated using a Single Roll Laboratory Coater. The silylated oil bath contained 3 wt. \% DBTDL and 3 wt. \% water. Under these conditions the viscosity of the oil bath increased to $120 \mathrm{cPs}$ and remained constant throughout the coating process. The coatings were cured in a short period of time when the papers were exposed to atmospheric moisture and post cured at $80^{\circ} \mathrm{C}$ in an oven. Close examination of the cured coated surface indicated that the coatings appeared to be very uniform with good adhesion to the cellulose fibers and with no apparent defects or run-offs.

Successful coatings using the Single Roll Lab Coater allowed us to evaluate the process on a larger scale Gravure coating system as shown schematically in Figure 2. The line speed and the oven temperature were adjusted to ensure a uniform coating and a complete cure to prevent the paper to stick on the collecting roll.

ATR FTIR scans of the coated and uncoated surfaces of the paper were run as preliminary tests to identify the success of the coating (Figure 5). It is apparent that the spectra of two surfaces appear very similar and is dominated by the broad absorption at $3300 \mathrm{~cm}^{-1}$ related to $\mathrm{O}-\mathrm{H}$ stretching vibration and the strong absorption at $1025 \mathrm{~cm}^{-1}$. Unfortunately, it is not possible to determine if the $\mathrm{O}-\mathrm{H}$ stretching vibration is related to the hydroxyl groups of the carbohydrates or the silanol groups obtained from the hydrolysis of the methoxy groups of the silane. Similarly, it is not

possible to determine if the strong absorption peak at $1025 \mathrm{~cm}^{-1}$ is related to $\mathrm{C}-\mathrm{O}$ stretching vibration of the cellulose fibers in the paper or the siloxane linkages ( $\mathrm{Si}-\mathrm{O}-\mathrm{Si}$ ) crosslinks. However, by subtracting the uncoated paper spectrum (A) from the coated spectrum (B) one can clearly observe the spectrum of the actual coating material. In Figure 5, Spectrum (C) is the result of the 
subtraction of uncoated paper spectrum (A) from the coated paper spectrum (B). Both, the subtraction spectrum (C) and spectrum (D) of neat cured silylated soy oil, are identical and clearly show the characteristics carbonyl $(\mathrm{C}=\mathrm{O})$ stretching vibration of the triglycerides at $1735 \mathrm{~cm}^{-1}$ confirming the presence of silylated soy oil coating on the coated substrate.

Comparing the FTIR spectrum of the silylated oil (Figure 6A) to the spectrum of the cured oil (Figure 6B) clearly indicates that all the silanols were condensed and the broad absorption peak around $3300 \mathrm{~cm}^{-1}$ has disappeared. Furthermore, the characteristic absorption of the methoxy functional groups at $1100 \mathrm{~cm}^{-1}$ that arises from the $\mathrm{CH}_{3}-\mathrm{O}$ stretching vibration and the $\mathrm{Si}-\mathrm{O}-\mathrm{CH}_{3}$ vibration between $750 \mathrm{~cm}^{-1}$ and $850 \mathrm{~cm}^{-1}$ have also disappeared as these methoxy silanes were reacted to yield the siloxane linkages of the cured product[44].

The Cobb values of these coated papers were determined (Table 1) and the results clearly demonstrate a significant decrease in the moisture absorption of the coated papers compared with the original, uncoated papers. It is apparent that small but statistically significant differences are observed in the Cobb values between the coatings prepared using the Single Roll Lab Coater and the coatings prepared using Gravure roll coater. We believe that these small differences are simply due to the difference in the operational conditions. The higher coat weight in the papers prepared in the Single-Roll Lab Coater undoubtedly contributed to the higher moisture resistance of the coated paper.

Not surprising is the inverse correlation between the Cobb values and the contact angle of the coating independent of the type of paper used (Figure 7). The contact angle of the uncoated Kraft papers is characterized by a typical hydrophilic contact angle of cellulose $\left(75-80^{\circ}\right)$. The relatively large variance in the contact angles here are most likely related to the surface characteristics of the uncoated Kraft papers, namely, the surface smoothness and homogeneity. The contact angles was 
significantly higher after coating for both papers (greater than $100^{\circ}$ ) as the silylated oil was embedded in the cellulose fibers and partly filled the paper pores resulting in a more hydrophobic character of these papers.

The WVTR of the silylated soybean oil cured coated papers showed that the coating led to a significant decrease of the paper moisture transfer. The transfer reduction for the Kraft paper \#60 was reduced by $47.7 \%$ and the WVTR for the Kraft paper \#78 was reduced by about $53.1 \%$ (Figure 8). Undoubtedly, this reduction in moisture transfer is due to the fact that many of the paper pores are filled by the cured oil. Consequently, water molecules can only cross the bulk paper by a lengthy and obstructed path which could explain the decrease of moisture transfer rates. Since the water penetration and absorption into the paper is largely depended on the homogeneity and internal structure of the coating, it is apparent that the silylated oil coatings still have an open structure. However, the improved water repellency here represents an intrinsic barrier properties which can further be enhanced by thicker coatings.

The surface of the papers after coating was examined by SEM and compared to the uncoated surface. It is apparent from the SEM micrographs (Figure 9) that the coating appears uniform with no evidence of holes or other imperfection and provided a complete coverage of the individual fibers with no apparent separation of the coating material from the paper fibers. Furthermore, the coating partially penetrated into the paper web and wrapped around the individual cellulose fiber bundles.

Typical film formation mechanism of aqueous dispersions or polymeric solutions generally consists of evaporation of the water (or the solvent) and consequent deformation of the film. This volume shrinkage can result in local stress concentration and often leads to undesirable cracks in the film coating. However, the relatively low viscosity of the silylated soybean oil allowed it to be 
used directly in the coating process. Thus, the only change in the volume of the coating material is the small loss of alcohol in the cure process resulting in a smooth crack-free crosslinked coating.

\section{Conclusions}

Moisture activated cure of silylated soybean oil was successfully prepared and used to enhance the moisture barrier of Kraft \#60 and Kraft\#78 papers. The cure rate of the silylated oil was directly proportional to the concentration of catalyst (DBTDL) and the water content. The coated Kraft papers showed a significant decrease in the Cobb values, indicating that these coating provide a good moisture barrier to the paper. SEM images show a complete coverage of the cellulose fibers of the paper with no apparent defects.

\section{Acknowledgment:}

We wish to acknowledge the generous funding from the Department of Defense (contract \# N00189-12-C-Z003) and the help of Northern Technologies International Corporation (NTIC) in scaling up the paper coating process.

\section{References}

[1] K. Khwaldia, E. Arab-Tehrany, S. Desobry, Biopolymer coatings on paper packaging materials, Comprehensive Reviews in food science and food safety, 9 (2010) 82-91.

[2] A. Bandyopadhyay, B. Ramarao, S. Ramaswamy, Transient moisture diffusion through paperboard materials, Colloids and Surfaces A: Physicochemical and Engineering Aspects, 206 (2002) 455-467.

[3] M. Kirwan, Paper and paperboard packaging, Food Packaging Technology, 5 (2003) 241. 
[4] J. Kuusipalo, A. Savolainen, E. Laiho, T. Penttinen, Extrusion coating and products, Paper and Paperboard Converting, 12 (2008) 108-166.

[5] J.O. Choi, F. Jitsunari, F. Asakawa, H.J. Park, D.S. Lee, Migration of surrogate contaminants in paper and paperboard into water through polyethylene coating layer, Food Additives \& Contaminants, 19 (2002) 1200-1206.

[6] D.T. Overcash, R.L. Elsenbaumer, Coated sheet method, in, US Patent 6,193,831, 2001.

[7] T. Schuman, M. Wikström, M. Rigdahl, Coating of surface-modified papers with poly (vinyl alcohol), Surface and Coatings Technology, 183 (2004) 96-105.

[8] G.L. Robertson, Food packaging: principles and practice, CRC press, 2012.

[9] T. Begley, K. White, P. Honigfort, M. Twaroski, R. Neches, R. Walker, Perfluorochemicals: potential sources of and migration from food packaging, Food additives and contaminants, 22 (2005) 1023-1031.

[10] K. Marsh, B. Bugusu, Food packaging_roles, materials, and environmental issues, Journal of food science, 72 (2007) R39-R55.

[11] J. Kester, O. Fennema, Edible films and coatings: a review, Food technology (USA), (1986). [12] J.M. Krochta, Proteins as raw materials for films and coatings: definitions, current status, and opportunities, Protein-based films and coatings, (2002) 1-41.

[13] K. Petersen, P.V. Nielsen, G. Bertelsen, M. Lawther, M.B. Olsen, N.H. Nilsson, G. Mortensen, Potential of biobased materials for food packaging, Trends in Food Science \& Technology, 10 (1999) 52-68.

[14] H. Benkreira, R. Patel, Direct gravure roll coating, Chemical engineering science, 48 (1993) 2329-2335.

[15] D.J. Coyle, Roll coating, Modern coating and drying technology, 3 (1992) 63-115. 
[16] E. Tekin, P.J. Smith, U.S. Schubert, Inkjet printing as a deposition and patterning tool for polymers and inorganic particles, Soft Matter, 4 (2008) 703-713.

[17] K. Miller, J. Krochta, Oxygen and aroma barrier properties of edible films: A review, Trends in Food Science \& Technology, 8 (1997) 228-237.

[18] F. Hussain, M. Hojjati, M. Okamoto, R.E. Gorga, Review article: polymer-matrix nanocomposites, processing, manufacturing, and application: an overview, Journal of composite materials, 40 (2006) 1511-1575.

[19] A. Arora, G. Padua, Review: nanocomposites in food packaging, Journal of Food Science, 75 (2010) R43-R49.

[20] M. Alam, D. Akram, E. Sharmin, F. Zafar, S. Ahmad, Vegetable oil based eco-friendly coating materials: A review article, Arabian Journal of Chemistry, 7 (2014) 469-479.

[21] D. Kaplan, Introduction to biopolymers from renewable resources, in: Biopolymers from renewable resources, Springer, 1998, pp. 1-29.

[22] J.D. Van Den Berg, N.D. Vermist, L. Carlyle, M. Holčapek, J.J. Boon, Effects of traditional processing methods of linseed oil on the composition of its triacylglycerols, Journal of separation science, 27 (2004) 181-199.

[23] G. Hutchinson, Traditional and new uses for vegetable oils in the surface coatings and allied industries, Surface Coatings International Part B: Coatings Transactions, 85 (2002) 1-8.

[24] J.-M. Raquez, M. Deléglise, M.-F. Lacrampe, P. Krawczak, Thermosetting (bio) materials derived from renewable resources: a critical review, Progress in Polymer Science, 35 (2010) 487509.

[25] J.T. Derksen, F.P. Cuperus, P. Kolster, Renewable resources in coatings technology: a review, Progress in Organic Coatings, 27 (1996) 45-53. 
[26] C. Stenberg, M. Svensson, E. Wallström, M. Johansson, Drying of linseed oil wood coatings using reactive diluents, Surface Coatings International Part B: Coatings Transactions, 88 (2005) 119-126.

[27] P. Muturi, D. Wang, S. Dirlikov, Epoxidized vegetable oils as reactive diluents I. Comparison of vernonia, epoxidized soybean and epoxidized linseed oils, Progress in organic coatings, 25 (1994) 85-94.

[28] M. Lazzari, O. Chiantore, Drying and oxidative degradation of linseed oil, Polymer degradation and stability, 65 (1999) 303-313.

[29] S.M. Meneghetti, R.F. de Souza, A.L. Monteiro, M.O. de Souza, Substitution of lead catalysts by zirconium in the oxidative polymerization of linseed oil, Progress in organic coatings, 33 (1998) 219-224.

[30] J. Mallégol, J.-L. Gardette, J. Lemaire, Long-term behavior of oil-based varnishes and paints. Photo-and thermooxidation of cured linseed oil, Journal of the American Oil Chemists' Society, 77 (2000) 257-263.

[31] H. Pelletier, N. Belgacem, A. Gandini, Acrylated vegetable oils as photocrosslinkable materials, Journal of applied polymer science, 99 (2006) 3218-3221.

[32] S.J. Park, F.L. Jin, J.R. Lee, Synthesis and thermal properties of epoxidized vegetable oil, Macromolecular Rapid Communications, 25 (2004) 724-727.

[33] R. Narayan, D. Graiver, K.W. Farminer, M. Srinivasan, Moisture curable oil and fat compositions and processes for preparing the same, in, US Patent 8,110,036, 2012.

[34] C. Tambe, S. Dewasthale, X. Shi, D. Graiver, R. Narayan, Silylation of Non-Terminal Double Bonds of Natural Oils, Silicon, (2015) 1-12. 
[35] G.L. Witucki, A silane primer: chemistry and applications of alkoxy silanes, Journal of coatings technology, 65 (1993) 57-57.

[36] H. Ni, A.D. Skaja, R.A. Sailer, M.D. Soucek, Moisture-curing alkoxysilane-functionalized isocyanurate coatings, Macromolecular Chemistry and Physics, 201 (2000) 722-732.

[37] S. Sterman, J.G. Marsden, Silane coupling agents, Industrial \& Engineering Chemistry, 58 (1966) 33-37.

[38] H. Hoffmann, The ene reaction, Angewandte Chemie International Edition in English, 8 (1969) 556-577.

[39] E.C. Keung, H. Alper, The Ene Synthesis, Journal of Chemical Education, 49 (1972) 97.

[40] B.B. Snider, G.B. Phillips, [1, 2]-Intramolecular ene reactions, The Journal of Organic Chemistry, 49 (1984) 183-185.

[41] T.M. Stefanac, M.A. Brook, R. Stan, Radical Reactivity of Hydrovinylsilanes: Homooligomers 1, Macromolecules, 29 (1996) 4549-4555.

[42] V. Rao, G. Babu, Copolymerization of styrene, acrylonitrile and methyl methacrylate with $\gamma$ methacryloxypropyl trimethoxy silane, European polymer journal, 25 (1989) 605-609.

[43] F. Osterholtz, E. Pohl, Kinetics of the hydrolysis and condensation of organofunctional alkoxysilanes: a review, Journal of Adhesion Science and Technology, 6 (1992) 127-149.

[44] A.L. Smith, Infrared spectra-structure correlations for organosilicon compounds, Spectrochimica Acta, 16 (1960) 87-105. 


\section{List of Figures and Tables}

Table 1: Cobb values for different papers

Scheme 1: Silylation of unsaturated fatty acid

Scheme 2: Network formation by hydrolysis and condensation of alkoxysilanes to siloxane crosslinks

Figure 1: Schematic representation of high pressure PARR reactor used for the silylation reaction

Figure 2: Schematic representation of the paper coating process. A: Back-up roll, B: Gravure roll,

C: Doctor's blade, D: Oven, E: Silylated soybean oil bath

Figure 3: Extent of grafting onto LowSat ${ }^{\circ}$ soybean oil as a function of time at $250^{\circ} \mathrm{C}$

Figure 4: Effect of water on the viscosity of silylated LowSat ${ }^{\circledR}$ soybean oil at different concentration of DBTDL catalyst $[\mathrm{A}=1 \mathrm{wt} . \% ; \mathrm{B}=2 \mathrm{wt} . \% ; \mathrm{C}=3 \mathrm{wt} . \% ; \mathrm{D}=4 \mathrm{wt} . \%]$

Figure 5: ATR-FTIR spectra of coated and uncoated Kraft papers [A]: Uncoated paper, [B]: Coated paper, [C]: Coated - Uncoated, [D]: Silylated soybean oil

Figure 6: FTIR spectra of [A]: Silylated soybean oil and [B]: final cured film

Figure 7: The 2 min Cobb values as a function of contact angle for different papers

Figure 8: Water Vapor Transmission Rate (WVTR) for coated and uncoated papers [Kraft \#60 and Kraft\#78]

Figure 9: SEM of the surface of uncoated paper (left) and coated paper (right) at different magnifications $[\mathrm{A}]: \mathrm{x} 70,[\mathrm{~B}]: \mathrm{x} 200,[\mathrm{C}]: \mathrm{x} 550$ 
Figure 1

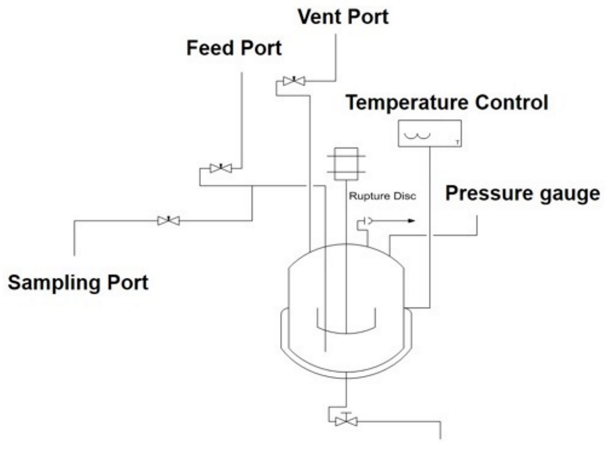

Drain 


\section{Figure 2}

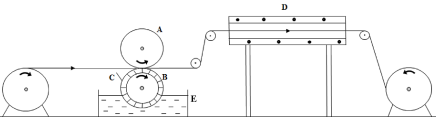


Figure 3

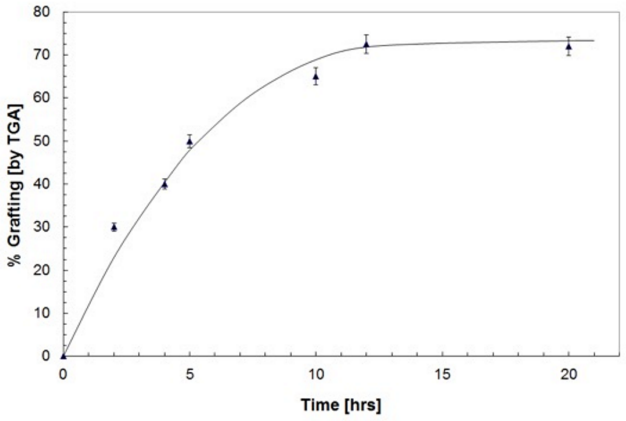


Figure 4
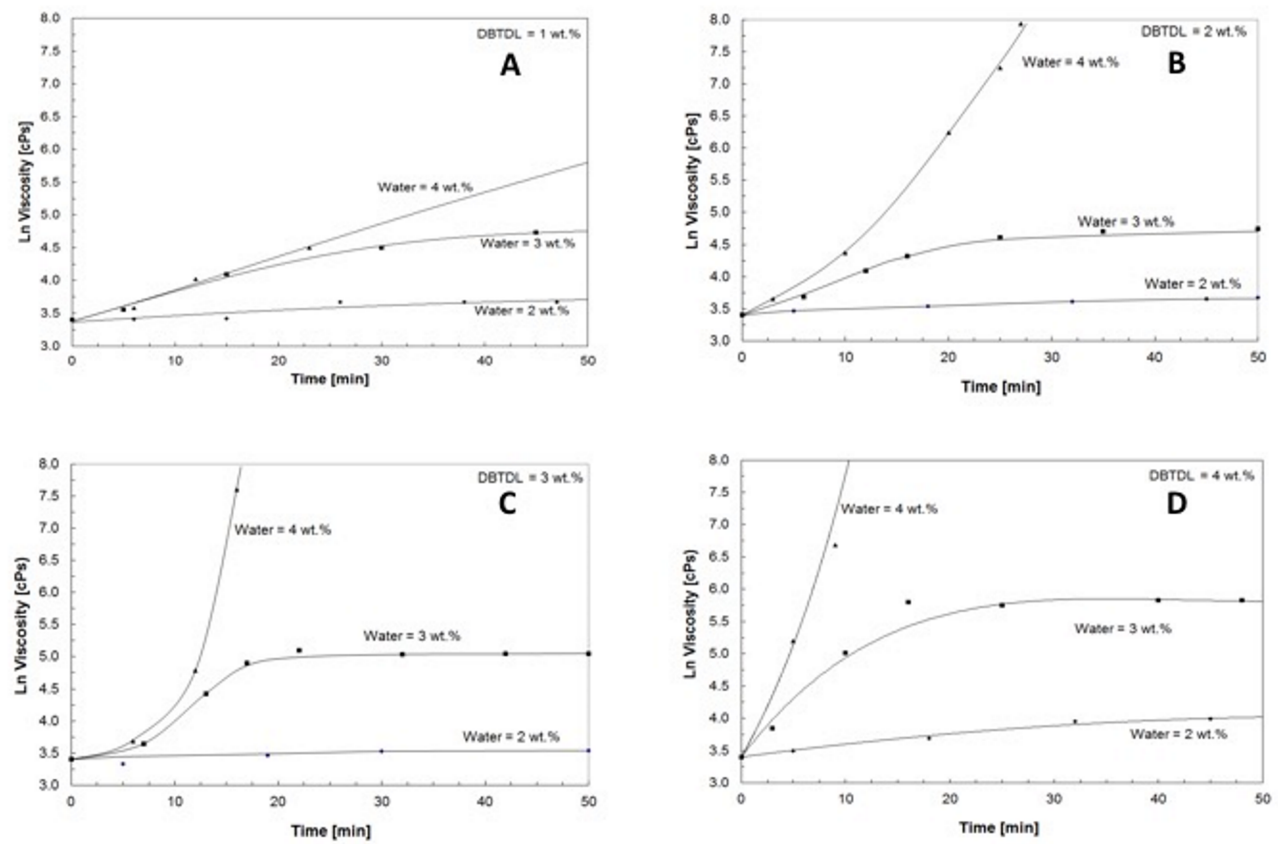
Figure 5

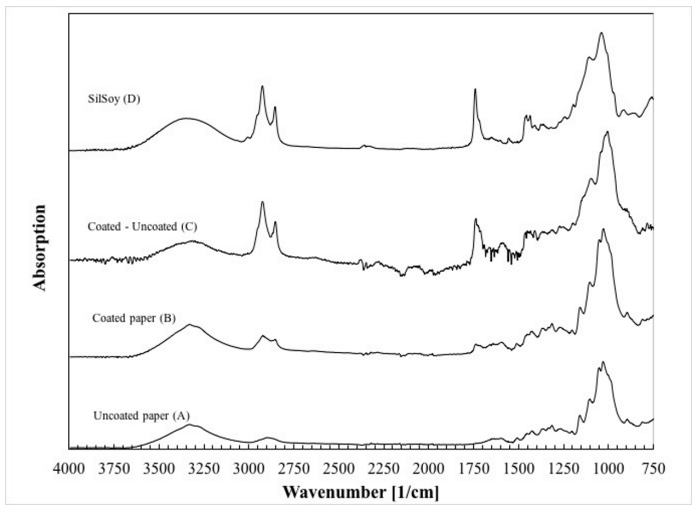


Figure 6

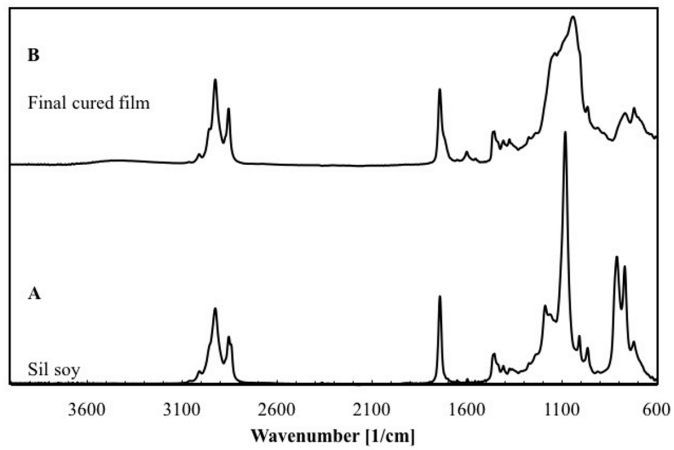


Figure 7

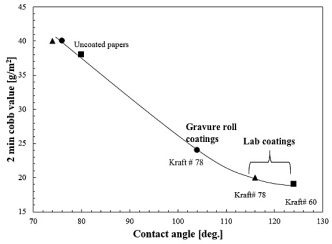


Figure 8

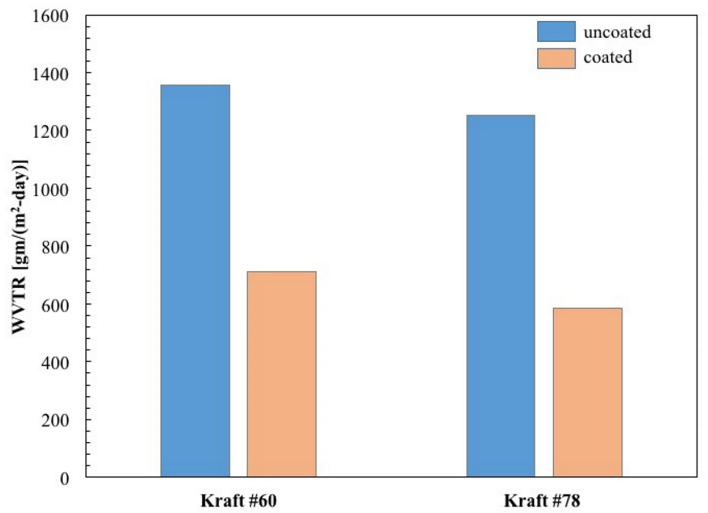


Figure 9

A
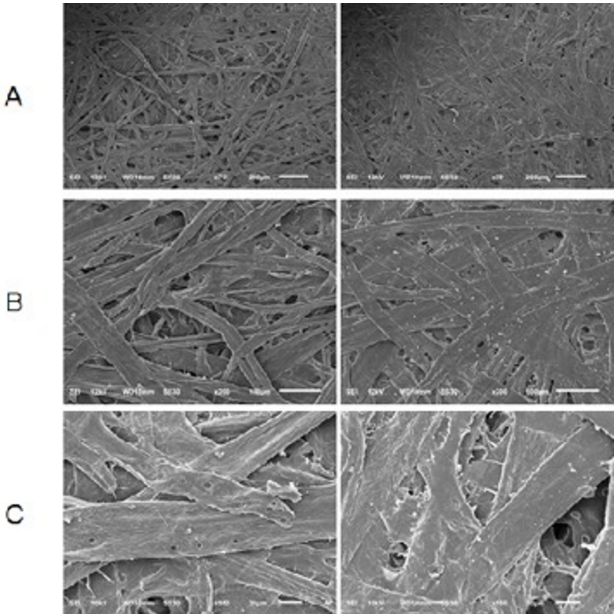


\section{Scheme 1}

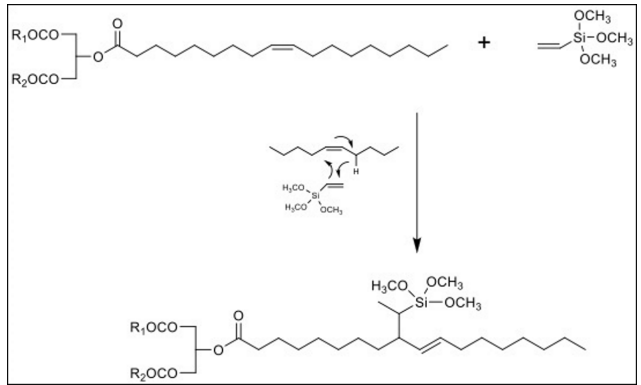




\section{Graphical Abstract}

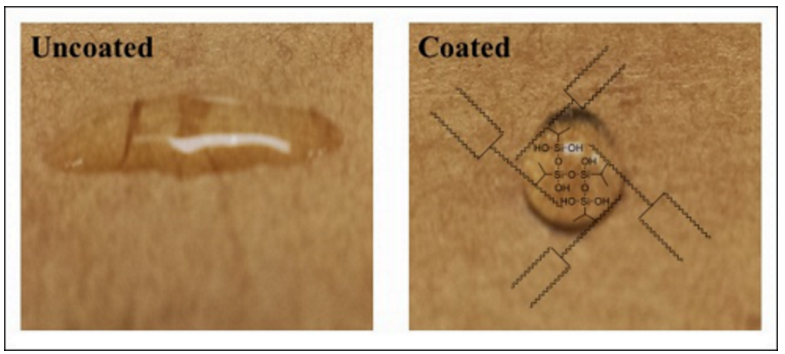

